\title{
LOS ANORMALES Y EL "DESARROLLO DE LA PASTORAL" DE FOUCAULT, COMO EXPRESIÓN PLÁSTICA EN EL JARDÍN DE LAS DELICIAS (1480-1490) DE EL BOSCO
}

The abnormal and "development of pastoral" of Foucault as plastic expression in The garden of earthy delights (1480-1490) by Hieronymus Bosch

\section{Daniel Montero Rodríguez*}

\section{RESUMEN}

El presente artículo analiza el texto pictórico El jardín de las delicias (1480-1490) del pintor neerlandés Jerónimo Bosch (1450-1516), El Bosco, a partir de los postulados teóricos de Michel Foucault. En primera instancia, se observan los componentes icónicos y su referencialidad, como parte de una visión de mundo determinada por lo sociocultural. Por otra parte, se estudia la relación de la pintura con el discurso religioso, dentro del desarrollo de la "pastoral" y la condición de la monstruosidad humana, explicadas por Michel Foucault en su texto Los anormales.

Palabras clave: iconografía-iconología, monstruosidad, discurso religioso, pastoral, El Bosco, Foucault.

\begin{abstract}
This article analyzes the pictorial text The Garden of Earthly Delights (1480-1490) painted by the Dutch painter Hieronymus Bosch (1450-1516), Bosch, from the theoretical postulates of Michel Foucault. In the first instance, iconic components and their referentiality, as part of a world view determined by the sociocultural, are observed. On the other hand, it is studied the relationship of painting with religious discourse, inside the development of the "pastoral" and the condition of human monstrosity, explained by Michel Foucault in his text Abnormal.
\end{abstract}

Key Words: iconography, iconology, monstrosity, religious, pastoral discourse, Bosch, Foucault.

Universidad de Costa Rica, Sede de Occidente. Profesor de Artes Plásticas. Costa Rica

Correo electrónico: danielmont84@gmail.com

Recepción: 23/7/14. Aceptación: 4/6/15. 


\section{Introducción}

Parte de lo que se hace al relacionar los conceptos teóricos de Michel Foucault con la obra artística del pintor neerlandés Jerónimo Bosch (El Bosco, 1450-1516), es estudiar la imagen como representación de algo, no solo como motivo efectivo de una cultura y época determinada, sino como un elemento de lectura que permita al receptor asirse del texto pictórico. Es decir, se pretende que el lector pueda ver más allá de sus percepciones, para profundizar en un conjunto de herencias conceptuales que le lleven a decodificar la obra artística como lectura de otros textos históricos.

Para este fin, es necesario comprender cómo cada cultura se expresa a través de las imágenes. Según Algirdas J. Greimas: “(...) cada cultura, al estar dotada de una «visión del mundo» que le es propia, les plantea también condiciones variables al reconocimiento de los objetos $\mathrm{y}$, con ello, a la identificación de las figuras «que representan» los objetos del mundo, conformándose a menudo con vagos esquematismos, pero exigiendo a veces una reproducción minuciosa de los detalles «verídicos»" (2002: 80). Sin embargo, estudiar la imagen solo referida a la exactitud cultural, social y temporal a la que pertenece, no es parte de lo que se pretende con el análisis de la obra El jardín de las delicias (1480-1490). No se busca desarrollar solo un análisis iconológico. Por el contrario, se estudia la imagen como una forma de texto desde donde se referencian no solo algunos signos culturales, sino saberes posteriores, los cuales buscan aprehender diferentes manifestaciones históricas. De este modo, al contemplar la imagen (pintura) como discurso, se podrán leer connotaciones diversas, sujetas al orden icónico e histórico.

Esto queda claro cuando Greimas refiere que, de cierto modo, la lectura icónica se abre a una libre interpretación: "Sin embargo, lo esencial está ahí: la cuestión de la figura de los objetos planares («imagen», «cuadro», etc.) sólo se plantea si se postula una cuadrícula de lectura iconizante y se le aplica a la interpretación de tales objetos, lo cual no es la condición necesaria de su apercepción y no excluye la existencia de otros modos de lectura igualmente legítimos" (2002: 80). De esta forma, se comprende cómo -con el estudio iconográfico y dejando de lado el estudio iconológico-, se establece la base sobre la cual se sustentarán saberes como los propuestos por Foucault.

\section{Delimitaciones conceptuales}

El presente análisis de la obra plástica se realiza a través de la comparación de la figura icónica con su referente. Para ello, se recurre a principios artísticos básicos, como: simetría, asimetría y elementos pictóricos como el color. Por ende, es necesario considerar al ícono como una forma de imitación de la realidad, pero entendido como un elemento no-real; esto al ser simplemente una imagen: "Así ocurre con el ícono, signo «naturalmente motivado» que representa al «referente», y con la iconicidad, concepto situado en el centro de los debates de la semiología de la imagen, y que remite de manera igualmente natural a la antigua «imitación de la naturaleza»" (Greimas, 2002: 78). Así, se analiza la imitación que realiza la imagen como referente del natural; es decir, ese juego falsoverdadero como mímesis.

Dentro de esta conceptualización, la percepción espacial que se tiene en la actualidad, es denominada por Foucault como "espacios diferentes": "No vivimos en el interior de un vacío coloreado por diferentes tornasoles, vivimos en el interior de un conjunto de relaciones que definen emplazamientos irreductibles unos con otros y no superponibles en absoluto" (1999: 434). De esta forma, estos espacios bien delimitados son catalogados por Foucault de dos formas: utopías y heterotopías. Tanto una noción como la otra serán usadas para comprender la manera cómo actúa la imagen en tanto referente de la realidad.

La pintura, como imagen referencial del mundo real, se comprenderá como un espacio utópico, el cual es definido por Foucault de la siguiente forma: "Las utopías 
son los emplazamientos sin lugar real. Son los emplazamientos que mantienen con el espacio real de la sociedad una relación general de analogía directa o inversa. Se trata de la misma sociedad perfeccionada o del reverso de la sociedad, pero de cualquier manera estas utopías son espacios fundamental y esencialmente irreales" (1999: 434). En este sentido, la imagen pictórica como utopía muestra la suposición de una realidad inexistente, pero idealizada de El Bosco. De este modo se comprende la representación de El jardín de las delicias, donde se muestra el cielo, la tierra y el infierno como esos espacios imaginados, irreales $\mathrm{y}$, hasta cierto punto, sublimados.

Por otra parte, la manifestación plástica también se entiende no solo como un espacio ficticio y utópico. Por el contrario, sirve como referencia del mundo real. En este sentido, cabe entender la imagen como ese espacio heterotópico del que habla Foucault:

(...) una especie de utopías efectivamente realizadas en las que los emplazamientos reales, todos los demás emplazamientos reales que es posible encontrar en el interior de la cultura, están a la vez representados, impugnados e invertidos, son una especie de lugares que están fuera de todos los lugares, aunque, sin embargo, resulten efectivamente localizables. Ya que son absolutamente distintos a todos los demás emplazamientos que ellos reflejan y de los que hablan, llamaré a estos lugares, en oposición a las utopías, heterotopías(...) (1999: 434)

Por eso, la pintura se comprende como representación utópica del cielo y la tierra; así se muestra como ese espacio heterotópico que emplaza el espacio utópico de la imagen con el de la realidad de quien la percibe como veraz.

Para comprender mejor cómo se plantean los espacios utópicos y heterotopicos, en relación con el espacio pictórico, es necesario distinguir la función de la imagen como representación, tanto "en la realidad" como "de la realidad", aunque esta sea ficticia. Esa función de la imagen como referente intermedio entre realidad e irrealidad, queda claramente explicada por Mauricio Vitta cuando la describe como un enigmático reflejo: "Copia, representación, similitud, símbolo, signo: la imagen no se define por lo que es, sino por aquello a lo que remite, su modelo, respecto al cual se revela, sin embargo, sólo como un enigmático reflejo. En consecuencia es ella misma, pero sólo en la medida en que se presenta como algo distinto" (2003: 33). Esto se relaciona con el ejemplo que brinda Michel Foucault sobre el espacio heterotópico, al relacionarlo con el espejo:

En el espejo me veo donde estoy, en un espacio irreal que se abre virtualmente tras la superficie; estoy allá lejos, allí donde no estoy, soy una especie de sombra que me da mi propia visibilidad, que me permite mirarme allí donde estoy ausente: utopía del espejo. Pero es igualmente una heterotopía, en la medida en que el espejo existe realmente y en que posee, respecto del sitio que yo ocupo, una especie de efecto de remisión (...) (1999: 435)

Así, el cuadro, en tanto pintura existente, se presenta ante el espectador como una remisión de la realidad. Pero, a su vez muestra una imagen utópica, al ser una simple representación. Posee la ficcionalidad e idealización de la sociedad donde surgió como proceso imaginativo del pintor. En este sentido, crear una obra pictórica es una manera de codificar un mensaje el cual, más que establecer una reminiscencia, se considera como verdadero, como imagen de la realidad. Según Gy Gauthier: "El problema sería simular la naturaleza, merced a la perfección de la codificación: la imagen debería dar, no la sensación de significar, sino de ser" (1996: 94). Es decir, la imagen se contempla como ese objeto real que representa una ficción, pero el cuales tomado como un referente efectivo de esa realidad.

La imagen se percibe no solo como una alegoría ficcional, sino como una realidad que se extiende ante el público; o sea, una ventana a una existencia más allá. Sobre esto, Vitta señala: "No obstante, damos por sentado que el cuadro «ha de representar» algo real. Estamos convencidos, a pesar de las disminuciones de la obra, de que se trata del estudio de un pintor, con el artista y la modelo en pleno trabajo" (2003: 60).Precisamente, esta percepción donde el espectador no entiende la imagen como 
tal, sino como algo real, es lo que posiciona a la pintura como un espacio heterotópico. Este juego entre lo real de la pintura y lo ficcional que representa, es lo que la convierte en parte de uno de estos espacios descritos por Foucault: "Las heterotopías tienen el poder de yuxtaponer en un solo lugar real varios espacios, varios emplazamientos que son por sí mismos incompatibles" (1999: 438).

\section{Explorando El jardín de las delicias}

Para entender mejor cómo se da esta relación entre el espacio descrito por Foucault y el espacio de la obra de El Bosco, es necesario hacer una lectura inicial del texto pictórico. En primera instancia, se debe observar el título de la obra: El jardín de las delicias. Para Michel Foucaul, "el jardín" es precisamente el mejor ejemplo de espacio heterotópico: “(...) pero acaso el ejemplo más antiguo de estas heterotopías, en forma de emplazamientos contradictorios, es el jardín. No hay que olvidar que el jardín, sorprendente creación ahora milenaria, tenía en Oriente significaciones muy profundas y que estaban como superpuestas" (1999: 438). Entonces, ¿qué tipo de significaciones podían estar superpuestas? Al analizar su simbología, se indica que: "El jardín es el ámbito de la naturaleza que aparece sometida, ordenada, seleccionada, cercada. Por esto constituye un símbolo de la conciencia frente a la selva (inconsciente), como la isla ante el océano" (Cirlot, 2000: 267). Con esto, se comprende ese juego de espacios superpuestos, consciente e inconsciente, real y ficticio.

A su vez, "el jardín" connota una percepción del mundo como especie de perfección, es decir, como esa utopía descrita por Foucault: "El jardín es la más pequeña parcela del mundo y después es la totalidad del mundo. El jardín es, desde lo más profundo de la Antigüedad, una especie de heterotopía, una especie de heterotopía feliz y universalizante (de ahí nuestros jardines zoológicos)" (1999: 438). De esta forma, la pintura de El Bosco se entiende como esa referencia no solo al jardín, sino a todo el mundo, incluso a toda la humanidad. Esto es planteado a través de la idealización de la felicidad humana en el cielo y los placeres del hombre en la tierra; de ahí la titulación de la obra El jardín de las delicias.

En segundo lugar, el cuadro muestra una serie de elementos y símbolos, los cuales establecen una perspectiva particular. A través de esta perspectiva, el espectador puede leer con facilidad la intención de la obra, decodificando las connotaciones y denotaciones que en este se emplean. Por ejemplo, para efectos de denotar la perfección del cielo, en el ala izquierda de la obra, el artista recurrió al uso del principio artístico de la simetría.

Cuando se estudian las relaciones simétricas y asimétricas de una obra pictórica, se observa que el principio simétrico connota apreciaciones de orden y equilibrio. Esto es descrito por Parini al referirse al estudio de una pintura: “(...) nos permite percibir toda la escena desde la antítesis categorial del orden y el desorden según un contraste que, en el plano compositivo, se revela con la compleja relación que se entabla entre simetría, asimetría y equilibrio" (2007: 297).Lo mismo se presenta al estudiar el conjunto de las tres tablas que componen El jardín de las deliciasde El Bosco: En el ala izquierda, se representa el cielo mediante una rigurosa composición simétrica, connotando orden y equilibrio; en la tabla central, se observa la tierra, con una simetría menos rígida; y finalmente, en la tabla del infierno (ala derecha), la asimetría es total, connotando desorden y pérdida de equilibrio. En esta última tabla, reina el caos.

La obra, a su vez, se vale del uso de la simetría y la asimetría para referir otro tipo de referente simbólico. Así, la simetría no solo denota equilibrio, sino poder y relaciones espirituales:

Hay que recordar que simetría y asimetría desempeñan un papel importante también desde el punto de vista iconológico e iconográfico, puesto que suelen expresar connotaciones de valor simbólico y espiritual, como cuando la simetría, por ejemplo, se convierte en metáfora reveladora de los aspectos más emblemáticos de la trascendencia 
en sus manifestaciones metafísicas y atemporales, o cuando, mediante formas estáticas o solemnes, se logra comunicar una sensación de autoridad o de poder. (Parini, 2002: 297)

De esta manera, se comprende con claridad por qué la pintura posee un uso más estricto de la simetría en la representación del ala izquierda; pues en esta, como representación del cielo, es donde se muestra el ícono de Dios. En consecuencia, mediante este principio compositor (la simetría), se propone tanto la imagen de Dios -como conjunto de relaciones espirituales y de orden-, así como su poder supremo.

Para precisar estas observaciones, es prudente referir la descripción realizada por Ingo F. Walther sobre El jardín de las delicias. De acuerdo con este analista, respecto al cielo: "Sólo el ala izquierda se inscribe en el mundo familiar de las representaciones cristianas: en el primer plano, Dios Padre une a Adán y Eva, para que vivan en armonía con la naturaleza todos los seres de la creación." (2005: 135). Así, Walther no solo plantea cómo se constituye la obra y -en cierto modo- la pragmática de la representación, al estudiar las relaciones simétricas y simbólicas, sino que a su vez propone esa relación de la utopía espacial, establecida por Foucault con los espacios diferentes. Sobre todo, cuando plantea en este espacio (el cielo) la perfección de las relaciones humanas. Por lo tanto, en el cuadro solo se aprecia a Dios en el centro de la composición, y a los lados Adán y Eva (hombre y mujer), como lo dicta la cristiandad.

Esta noción de lo prefecto, en la obra, se da a través de la idealización de las relaciones sexuales como exclusivas de las personas heterosexuales. A su vez, esto se asocia con las reflexiones de Foucault en Los anormales, y la forma como plantea el desarrollo de la monstruosidad del ser. Según Foucaul, la normalidad se da mediante el binomio hombre/ mujer, pues se ha concebido como analogía desorden/naturaleza: “(...)la afirmación de que el hermafrodita es un monstruo. Esto figura en el discurso de Riolan, que dice que lo es porque es contrario al orden y la regla corriente de la naturaleza, que separó el género humano en dos varones y mujeres" (Foucault, 2000: 77). Tanto en la pintura de El Bosco como en el estudio de Foucault, se establece la naturaleza como parámetro que regula al ser humano, a través de un estricto orden que llevaría a alcanzar esa utopía de la normalidad y la perfección.

En este sentido, Foucault clasifica "lo monstruoso" en una serie de tipologías, a saber: "monstruo humano", "individuo a corregir" y el "masturbador". Por ende: "En el fondo, esos tres elementos son tres figuras o, si lo prefieren, tres círculos dentro de los cuales, poco a poco, va a plantearse el problema de la anomalía" (Foucault, 2000: 61). Estas categorías de lo monstruoso se observan en la pinturaEl jardín de las delicias de El Bosco, espacialmente el "monstruo humano". Dicha categoría establece la forma icónica con la cual se representa no solo al "monstruo" o "anormal", sino al pecador. De este modo, el artista relaciona la figura pecaminosa del ser, con la imagen visual de un monstruo.

En la tabla donde se representa a la tierra, en comparación con el ala izquierda del cielo, es posible identificar no solo una disminución de la simetría, sino un aumento en el número de seres representados, los cuales son de diversos tipos: hombres, mujeres, animales, seres alados y sirenas. En este caso, se denota el mundo como un conjunto de relaciones donde el hombre está expuesto a la tentación y el pecado. Tanto las sirenas como los seres alados, al responder a personajes compuestos (es decir, son mitad humanos y mitad animales) pueden asociarse con esa monstruosidad establecida por Foucault:

Desde la edad media hasta el siglo XVIII que nos ocupa es, esencialmente, la mezcla de dos reinos, reino animal y reino humano: el hombre con cabeza de buey, el hombre con patas de pájaro -monstruosEs la mixtificación de dos especies, la mezcla de dos especies: el cerdo que tiene cabeza de carnero es un monstruo. Es la mixtura de dos individuos: el que tiene dos cabezas y un cuerpo, el que tiene dos cuerpos y una cabeza, es un monstruo. (2000: 68)

Tanto para Michel Foucault como para Jerónimo Bosch, la mixtificación es un rasgo propio de lo monstruoso y, a la vez, representa 
las delicias, el pecado y la anormalidad como elementos propios de la tierra y la realidad. El pintor neerlandés se vale de estas iconografías para expresar una intención sistemáticosemántica particular. Por ejemplo, la figura mítica de las sirenas: "Pueden representar lo inferior en la mujer y la mujer como lo inferior, cual en el caso de las láminas; son también símbolos de la imaginación pervertida y atraída por la finalidades inferiores, por los estratos primitivos de la vida" (Cirlot, 2000: 419). Por ende, estas imágenes se analogan a la perversión, lo inferior. Son la representación del mal en la tierra, o sea aquellos seres que serán condenados por su transgresión a la norma natural.

En otro sentido, la sirena no solo simboliza lo primitivo e infame; también se relaciona con la sensualidad y el placer: "Son también símbolos del deseo, en su aspecto más doloroso que lleva a la autodestrucción, pues el cuerpo anormal no puede satisfacer los anhelos que su canto y su belleza de rostro y busto despiertan" (Cirlot, 2000: 419). En consecuencia, el placeres visto como una forma de tentación "por" y "para" el cuerpo, la cual no puede ser satisfecha debido a su propia anormalidad. Esta forma del cuerpo como deseo tiene una relación directa con el título del texto pictórico, puesEl jardín de las delicias se relaciona con lo terrenal como "zona de deseos" o "Edén de placeres".

Walther describe el espacio terrestre, representado en la obra de El Bosco, precisamente como ese espacio de los goces:"En cualquier caso, la tabla central presenta a la humanidad dándose a los placeres de los sentidos, representados en inagotables variaciones, cuya comprensión se revela en su contemplación" (2005: 135).Esta pintura de El Bosco, permite una lectura relacionada con el trabajo de Michel Foucault, específicamente con el desarrollo de la "pastoral", cuando explica como el cuerpo se ha concebido como centro del deseo y del placer; es decir, es el provocador del desvió del ser humano: "En cierto modo, el cuerpo y sus placeres se convierten en el código de lo carnal mucho más que la forma exigida para la unión legítima" (Foucault, 2000: 179). Por lo tanto, el cuerpo -como medio del placer y como forma carnal-, es definido por un sentido perverso: “(...) la sensualidad el propio cuerpo. A partir de ahí se comprende, entonces, cómo se produce otro desplazamiento muy importante. Es que, en adelante, el problema esencial dejará de ser la distinción que ya preocupa a los escolásticos: acto real y pensamiento. El problema va a ser: deseo y placer" (Foucault, 2000: 182). A pesar de que, hasta cierto punto, Foucault asocia este deseo con la masturbación, también se puede identificar con la analogía cuerpo-placer-deseo, que se observa en la obra de El Bosco, tanto a través de la sensualidad simbólica de la sirena, como con la presencia del desnudo de todos los seres representados en la obra.

Michel Foucault confirma el sentido del cuerpo como portador de placer. Esta noción puede proporcionar una lectura del goce asociada a la imagen pictórica de la sirena. En este sentido, existe una relación temporal muy cercana entre el desarrollo pastoral tridentina del siglo XVI, con la pintura de esa época: "Al contrario, lo que hay de nuevo a partir de la pastoral tridentina y el siglo XVI es esta tecnología del alma y el cuerpo, del alma en el cuerpo, del cuerpo portador de placer y deseo" (2000: 185). El cuerpo es, entonces, un elemento de tentación del ser; así, las "delicias" en el "jardín" responden al juego del hombre con el placer y el pecado; igual ocurre en el mundo con lo anormal, lo monstruoso y lo perverso, o sea todo lo que es condenado al infierno.

En la tabla central de la pintura de El Bosco, correspondiente a la tierra, la presencia de seres diversos es evidente, tanto humanos (normales) como animales, sirenas y seres alados; es decir, coexisten normalidad, anormalidad y lo monstruoso. Esta característica es clara diferencia con el cielo y el infierno. En el cielo, el pintor representa el Edén habitado solo por Dios, Adán y Eva (estos últimos perfectamente bien hechos, sin anormalidades ni mixturas). De algún modo, esta imagen tiene un carácter didáctico-ejemplificador para el público. Por el contrario, el infierno está lleno de seres monstruosos, malformados o sodomizados. Por esta razón, se puede comprender por qué Ingo F. Walther afirma que: "En el ala de la derecha, 
El Bosco ha pintado los tormentos del infierno, a los que se ve expuesta toda la humanidad. Aquí no hay justos y pecadores, como en las representaciones del Juicio Final, sino sólo condenados sin esperanza de salvación" (2005: 135). En consecuencia, el autor asegura que en esta imagen solo están los condenados, pues responde a los íconos de todos los seres anormales: chanchos con velos de mojan, ratones y conejos con trajes de hombre, seres que devoran y defecan hombres, personas mitad hombre mitad árbol y varios sodomizados.

"El infierno" de El jardín de las delicias propone dos sentidos. En primer lugar, establece una diferencia en la composición. Al encontrarse en completa asimetría, es desorden, caos y anormalidad. Por otra parte, la imagen aparece en completa oscuridad, contrario a los espacios de "El cielo" y "La Tierra", los cuales comparten un mismo horizonte y una misma luz de día. "El infierno" se encuentra en la penumbra y la sombra de la noche.

"En combinación con el círculo de agua y jinetes, da un cierto orden a la inextricable variedad de figuras. Por el contrario, el infierno no mantiene ninguna relación con las otras tablas: es una representación nocturna sin esperanza del menor rayo de luz" (Walter, 2005: 135).Esta descripción realizada por Walther, señala otro elemento pictórico utilizado en la composición, el cual expone esa visión del espanto y de los horrores del infierno: "el color".

Cuando se estudia el significado de la "oscuridad", se comprende la inclinación del pintor por este modo de representación: "Las tinieblas -anteriores al fiat lux- expresan siempre, en el simbolismo tradicional, el estado de las potencias no desenvueltas que dan lugar al caos. Por ello, las oscuridad proyectada en el mundo ulterior a la aparición de la luz es regresiva; por ello se identifica tradicionalmente con el principio del mal y con las fuerzas inferiores no sublimadas" (Cirlot, 2000: 351). Esta imagen oscura solo refuerza ese caos y desorden representado con la asimetría de la imagen y con sus deformadas iconografías (como los anormales-monstruosos).

En cuanto a esta manifestación icónica de la monstruosidad que se observa en la tabla de "el infierno", en El jardín de las delicias de El Bosco, es reconocible la presencia de diversos monstruos mixtificados, a partir de la denominación de Foucault. Esto lo refuerza Walter, cuando explica:"En el centro aparece un monstruo despojado de toda figura humana, con el cuerpo vaciado y con un disco sobre la cabeza, en el que bailan pequeños monstruos, mientras que las piernas, transformadas en troncos de árboles, se encuentran en dos barcos" (2005: 135). La delineación literal que se hace de esta iconografía ayuda a establecer un vínculo entre representación como espacio real y la heterotopía manifiesta en una realidad utópica, donde la monstruosidad icónica representa a la monstruosidad del ser humano y al pecado. Estos monstruos (sirenas, seres alados, animales personificados, o seres amorfos), corresponden no solo a la monstruosidad del ser, sino a la infracción a la norma o interdictos, tanto en el plano natural como en el sentido social; tal como explica Michel Foucault:

\footnotetext{
La infracción jurídica a la ley natural no basta -para el pensamiento de la Edad Media, sin duda, y a buen seguro para el de los siglos XVII y XVIIIpara constituir la monstruosidad. Para que la haya, es preciso que esa transgresión del límite natural, esa transgresión de la ley marco sea tal que se refiera a, o en todo caso ponga en entredicho, cierta prohibición de la ley civil, religiosa o divina, o que provoque cierta imposibilidad de aplicar esa ley civil, religiosa o divina. Sólo hay monstruosidad donde el desorden de la ley natural toca, trastorna, inquieta el derecho, ya sea el derecho civil, el canónico o el religioso. (2000: 68)
}

La violación de las leyes de la naturaleza, coincide con la pérdida total de ese orden que proporciona el propio jardín. Dicho orden se obtienen al separar lo consiente ("cercadodispuesto") de lo inconsciente ("selva"). Por ende, lo monstruoso se genera al transgredir no solo la ley biológica, sino la ley social y la propia ley religiosa. Las relaciones de transgresión, monstruosidad y pecado propuestas por Foucault, pueden ser evaluadas icónicamente en las representaciones de El Bosco, en El Jardin de las delicias. De este modo, la pintura mantiene un sentido análogo con la propuesta de Foucault en Los anormales(2000). 


\section{Conclusiones}

A través de este análisis se puede afirmar que, el estudio de la relación entre ícono y semántica socio-cultural, permite establecer una concordancia entre pintura y discurso religioso. Así, la representación pictórica se propone como medio para el establecimiento de una determinada visión de mundo, la cual -de cierta forma-, muestra una especulación propiamente religiosa. Sobre esto, Sidney Finkelstein explica el uso de la imagen como una forma de representación religiosa $\mathrm{y}$, a su vez, una manifestación de poderes jerárquicos:

\begin{abstract}
Así, pues, de la misma necesidad que la Iglesia tenía de propagar sus doctrinas entre el pueblo nace un conflicto en la esfera de la superestructura ideológica de la sociedad medieval. De un lado, se nos ofrece la importante representación gráfica del cielo, con sus jerarquías -Dios, Jesucristo, los apóstoles, los santos y los ángeles-, a imagen de la jerarquía feudal, y el trasunto de los terribles castigos del "juicio final" con el ámbito de aterrorizar a la gente. (1969: 85)
\end{abstract}

Haciendo a un lado la propuesta de la jerarquía feudal, Finkelstein asocia la manifestación pictórica con las creencias religiosas, a modo de simbiosis lógica. Esto aparece tanto como apropiación temática en la pintura, así como un uso del poder fáctico de la imagen que la iglesia realiza; es decir, se emplea la imagen como medio de comunicación, para transmitir el pensamiento cristiano.

Este uso del elemento pictórico por parte de la iglesia, permite el reconocimiento de su función como promotora $y$, a la vez, vigía de las relaciones humanas. La iglesia traza el proyecto de regular el comportamiento de los seres humanos, evitando que se transformen en monstruos devorados por el infierno. Esta misma idea es planteada por Michel Foucault, cuando propone el trabajo del sacerdote como guía de salvación para las almas:

De allí el formidable desarrollo de la pastoral, es decir, de la técnica que ese propone al sacerdote para el gobierno de las almas. En el momento en que los Estados están planteándose el problema técnico del poder a ejercer sobre los cuerpos y los medios por los cuales podría ponerse efectivamente en acción ese poder, la Iglesia, por su lado, elabora una técnica de gobierno de las almas que es el pastoral, definido por el Concilio de Trento y retomado, desarrollado a continuación por Carlos Borromeo. (2000: 168)

El poder pastoral planteado por Foucault, se relaciona no solo con el poder de gobernar almas de una forma inquisitiva, sino que se concibe como un trabajo de guía. Esto ya que el sacerdote, en analogía simbólica con Jesucristo, es el pastor de las almas; o sea, es quien tutela los pasos de los fieles por el camino de la vida (en El jardin de las delicias), hacia el encuentro con el Dios supremo. En este sentido, se debe comprender la labor del clérigo según su "poder pastoral" y su función como confesor: "Así pues, sabio como juez y como médico, tiene que serlo también «como guía». Puesto que debe «ordenar la conciencia de sus penitentes». Tiene que «recordarles sus errores y sus extravíos». Debe «hacerles evitar los escollos» que se le presentan" (Foucault, 2000: 171).

La función pastoral de la iglesia católica, permite la comprensión de la imagen pictórica como medio de comunicación y transmisión de ideas. En el caso de El jardín de las delicias de El Bosco, se proyecta ese anhelo de la iglesia por mostrar al pueblo el modelo conductual de lo correcto y lo incorrecto, de lo monstruoso y normal.

Esta simbiosis entre discurso religioso y pintura es explicada por Mauricio Vitta como la imagen de un "sermón mudo":

\footnotetext{
A pesar de estas reservas, en los primeros siglos la cultura cristiana asumió la descomunal tarea de articular no sólo una doctrina coherente, sino también un sistema iconográfico dotado de pertinencia. El valor didáctico y educativo de las imágenes fue objeto de su atención desde el principio. No se admitía su veneración, pero se aceptaba la idea de que éstas podían hacer las veces, según la antigua tradición, de «sermón mudo». (2003: 127)
}

La pintura es la forma de catequizar al espectador sin palabras. Las imágenes funcionan como modelos a través de las cuales el sacerdote orienta el pensamiento de sus feligreses. Por otro lado, el sacerdote no interfiere en la creación pictórica, como lo hace el pintor como productor. Sin embargo, no se puede 
considerar que estos actúan en forma fáctica (en contacto directo con el espectador), pues el público es expuesto a la imagen $\mathrm{y}$, a partir de ahí, descubre e interpreta el discurso religiosopictórico. Por lo tanto, se puede decir que la obra plástica -como medio de representación- cumple una "función pastoral" en la medida que, en primer lugar, se encarga de mostrarlos placeres mundanos $\mathrm{y}$, en segunda instancia, propone el poder de Dios como orden y perfección para, finalmente, revelar las consecuencias de una vida desordenada y pecadora.

La obra plástica El jardín de las delicias expone, a través de una serie de principios pictóricos y elementos iconográficos, las creencias cristianas: cielo, vida terrenal e infierno. En estos, se establecen tanto los modelos de perfección humana (Dios, Adán, Eva y Edén), así como las consecuencias terroríficas de una vida pecaminosa y desordena. Este segundo modelo pedagógico (el infierno), se representa por medio de la asimetría, la oscuridad y la monstruosidad del ser humano. Estas características remiten conceptualmente a la tesis de Michel Foucault en su texto Los anormales, donde explica la noción de "monstruo humano". La obra artística de El Bosco se establece como un "espacio heterotópico", mezclando -a modo de emplazamiento- tanto espacios referenciales como espacios propios de la obra-objeto; es decir, espacios donde la imagen bidimensional simula la tridimensional; y "espacios utópicos" donde se refieren otros idealizados y ficticios. De esta manera, El Bosco presenta su texto pictórico como una especie de texto catequizador, el cual -en cierta medida- contiene el principio religioso-pedagógico de la evangelización. Así, se puede leer como un tipo de "poder pastoral", según la propuesta de Michel Foucault; o sea, es una especie de texto pictórico ejemplarizante y disciplinador de la conducta humana.

\section{Bibliografía}

Cirlot, Juan Eduardo. 2000. Diccionario de símbolos. Barcelona: Ediciones Siruela.

Finkelstein, Sidney. 1969. El realismo en el arte. México: Editorial Grijalbo.

Foucault, Michel. 1999. Estética, ética y hermenéutica. Barcelona: Paidós Básica.

Foucault, Michel. 2000. Los anormales. México: Fondo de Cultura Económica.

Gauthier, Gy. 1996. Veinte lecciones sobre la imagen y el sentido. Madrid: Cátedra.

Greimas, Algirdas J. 2002. "Semiótica figurativa y semiótica plástica". En: Desiderio Navarro (comp.). Imagen 1. Teoría francesa y francófona del lenguaje visual y pictórico, La Habana, Cuba,Criterios; 73-97.

Parini, Pino. 2002. Los recorridos de la mirada. Barcelona: Ediciones Paidós-Ibérica.

Vitta, Mauricio. 2003. El sistema de las imágenes. Barcelona: Paidós.

Walther, Ingo F. 2005. Los maestros de la pintura occidental. Del gótico al Neoclásico. Tomo I. Madrid: Taschen.

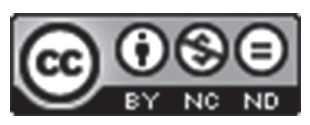

Este obra está bajo una licencia de Creative Commons Reconocimiento-NoComercial-SinObraDerivada 4.0 Internacional. 
